\title{
TERAPI STIMULASI KOGNITIF UNTUK LANSIA DENGAN MILD COGNITIVE IMPAIRMENT: STUDI EKSPERIMENTAL DI PANTI WREDA
}

\author{
COGNITIVE STIMULATION THERAPY FOR ELDERLY WITH MILD COGNITIVE \\ IMPAIRMENT: AN EXPERIMENTAL STUDY IN NURSING HOME
}

\author{
Nathalie Sanchia, * Magdalena Surjaningsih Halim*
}

\begin{abstract}
Introduction: Mild cognitive impairment (MCI) is a transitional stage between the elderly's normal (expected) cognitive decline and the more serious decline caused by dementia that needs interventions. One of the non-pharmacological interventions that can be done is cognitive stimulation therapy (CST). Research has shown that CST can stabilize and/ improve cognitive function in the elderly with $M C I$.

Aims: To find out the differences in cognitive functions in the elderly with MCI and given CST intervention and elderly with MCI not given CST intervention.

Methods: This was an experimental study that included elderly aged 60 years old divided into experimental and control group, each consists of four subjects. The experimental group was given CST twice a week with a total of fifteen meetings, but not on the control group. All subjects were subjected to cognitive examinations using neuropsychological instruments before, after, and one month after CST was completed. The statistical analysis performed in this study was Mann-Whitney U Test.
\end{abstract}

Results: There was a significant difference in cognitive function in the attention domain with the trail making test sub-test and the memory domain with the digit pan sub-test after the CST is finished. One month after CST is completed, there were significant differences in cognitive function, in the memory domain.

Discussion: The elderly group with MCI given CST has a different cognitive function than elderly group who are not given CST.

Keywords: Cognitive function, elderly, mild cognitive impairment, nursing house

\section{ABSTRAK}

Pendahuluan: Gangguan kognitif ringan atau mild cognitive impairment (MCI) merupakan proses transisi antara penurunan kognitif normal dan demensia yang perlu diintervensi. Salah satu intervensi non-farmakologis yang dapat dilakukan adalah cognitive stimulation therapy (CST). Banyak penelitian menunjukkan bahwa CST dapat menstabilkan dan/meningkatkan fungsi kognitif pada lansia dengan MCI.

Tujuan: Untuk mengetahui pengaruh intervensi CST terhadap fungsi kognitif lansia dengan MCI.

Metode: Studi eksperimental pada subjek lansia usia 60 tahun yang dibagi menjadi kelompok eksperimen dan kontrol yang masing-masing terdiri dari 4 subjek. Kelompok eksperimen dilakukan CST dua kali seminggu sebanyak lima belas kali pertemuan, tidak pada kelompok kontrol. Seluruh subjek dilakukan pemeriksaan kognitif dengan menggunakan instrumen neuropsikologi sebelum, sesudah, dan satu bulan setelah CST selesai. Analisis statistik menggunakan MannWhitney U test.

Hasil: Terdapat perbedaan fungsi kognitif yang signifikan pada domain atensi dengan subtes Trail Making Test dan domain memori dengan subtes digit span setelah CST selesai. Satu bulan setelah CST selesai, terdapat perbedaan fungsi kognitif yang signifikan pada domain memori.

Diskusi: Kelompok lansia dengan MCI yang diberikan CST memiliki fungsi kognitif yang berbeda dengan kelompok lansia yang tidak diberikan CST.

Kata kunci: Fungsi kognitif, gangguan kognitif ringan, lansia, panti wreda

*Fakultas Psikologi Universitas Katolik Indonesia Atma Jaya. Korespondensi: nathalie.sanchia@gmail.com.

\section{PENDAHULUAN}

Gangguan kognitif ringan atau mild cognitive impairment $(\mathrm{MCI})$ merupakan keadaan transisi antara penurunan kognitif normal dengan demensia ringan, sehingga berisiko tinggi untuk berkembang menjadi demensia. ${ }^{1-2}$ Pasien yang dapat dideteksi pada tahap MCI dapat dilakukan intervensi untuk memperlambat laju penurunan sejak dini. Terapi farmakologis memiliki keterbatasan untuk menstabilkan pasien $\mathrm{MCI},{ }^{3-4}$ maka dapat dengan cara menjaga asupan 
nutrisi, diet, melakukan aktivitas fisik dan mental, serta bersosialisasi. ${ }^{3}$

\section{Cognitive stimulation therapy (CST) adalah} sebuah program yang melibatkan peserta dalam diskusi mengenai kegiatan atau tugas seharihari sebagai usaha untuk menstimulasi aktivitas mental. Penelitian menunjukkan bahwa kelompok yang diberi stimulasi otak akan lebih baik fungsi kognitifnya dibandingkan dengan kelompok yang hanya diberi obat saja. ${ }^{5-6}$ Intervensi preventif untuk memperlambat MCI menjadi demensia akan menghasilkan penghematan secara finansial, karena mengurangi biaya perawatan jangka panjang serta biaya untuk fasilitas rumah sakit. ${ }^{7}$

Penelitian menunjukkan bahwa CST adalah intervensi yang efektif, namun studi yang asli sangat minim keragaman subjek karena menggunakan lansia di Eropa (Inggris). ${ }^{8}$ Oleh karena itu, implementasi CST sangat disarankan untuk diadaptasi sesuai dengan budaya negara yang sesuai. ${ }^{9}$ Jumlah lansia di Indonesia mencapai 9,27\% atau 24,49 juta jiwa pada tahun 2018 dan sebagian besar lansia memiliki pendidikan rendah. ${ }^{10} \mathrm{Hal}$ ini perlu dipertimbangkan dalam mengimplementasikan CST di Indonesia, mengingat inti dari intervensi CST adalah melakukan diskusi pada setiap tema yang diberikan.

Di Indonesia, tempat perawatan lansia dilakukan dipanti wreda yang didirikan oleh pemerintah maupun swasta. Jumlah lansia yang cenderung meningkat setiap tahunnya membuat panti wreda mengalami tantangan dalam pelayanan kesehatan. Lansia yang tinggal di panti menjadi kurang beraktivitas, baik aktivitas fisik, sosial, maupun kognitif, sehingga berisiko lebih besar untuk mengalami gangguan kognitif dibandingkan dengan lansia yang tidak tinggal di panti. ${ }^{11-12}$ Mengingat panti wreda belum memiliki program intervensi psikososial yang terstruktur untuk mencegah lansia menjadi demensia, maka perlu dilakukan studi awal mengenai CST pada lansia dengan MCI di panti wreda.

\section{TUJUAN}

Untuk mengetahui pengaruh intervensi CST terhadap fungsi kognitif lansia dengan MCI.

\section{METODE}

Desain penelitian ini adalah studi eksperimental terhadap lansia di daerah Jakarta Barat dan Jakarta Timur pada bulan Februari hingga Juni 2019. Subjek dikelompokkan menjadi kelompok eksperimen (KE) yang berasal dari Panti Sosial Tresna Wreda 2 (PSTW 2), Cengkareng dan kelompok kontrol (KK) berasal dari Panti Sosial Tresna Wreda 1 (PSTW 1), Cipayung. Kriteria inklusi adalah lansia berusia 60 tahun yang sudah didiagnosis sebagai MCI, dapat membaca dan menulis, tidak mengalami gangguan psikiatri ataupun gangguan neurologis selain MCI, tidak mengalami gangguan kondisi medis yang kronik ataupun gangguan mayor pada penglihatan, pendengaran, maupun gerakan anggota tubuh bagian atas, serta dapat berbahasa Indonesia sehari-hari.

Program CST yang asli terdiri dari 14 sesi yang terstruktur. Setiap sesinya memiliki durasi 45 hingga 60 menit dalam sebuah kelompok kecil sebanyak 5-8 subjek. Setiap sesi harus bersifat kontinu. Oleh karena itu, fasilitator harus memberikan aktivitas yang sama setiap sesinya, misalnya dengan aktivitas pemanasan (warm up), reality orientation board ( $\mathrm{RO}$ ) yang berisi mengenai informasi dari grup, dan orientasi (tanggal, waktu, dan cuaca). Fasilitator dalam CST diharapkan dapat mengikuti 18 prinsip yang telah disusun untuk menghadapi subjek. ${ }^{13}$

Penulis bersama neurolog dan psikolog melakukan focus group discussion (FGD) untuk melakukan adaptasi dan modifikasi terhadap modul CST yang asli. Dari hasil FGD diujicobakan sebuah tema, yaitu kekerabatan. Kegiatan CST dilakukan dengan tambahan tema tersebut sebanyak 15 pertemuan, lalu dilakukan evaluasi pelaksanaan sebagai dasar untuk melakukan pengembangan modul.

Kelompok eksperimen mendapat intervensi CST dua kali seminggu sejumlah lima belas kali pertemuan, sementara kelompok kontrol tidak mendapatkan terapi apa-apa. Semua subjek dilakukan pemeriksaan kognitif sebelum (pretest), sesudah (posttest), dan satu bulan setelah kelompok eksperimen mendapatkan CST (follow-up) menggunakan Neuropsychology Battery Test, yaitu 1) Trail Making Test (TMT) serta Bourdon dan Stroop Test untuk mengukur fungsi 
atensi, 2) Boston Naming Test (BNT), Token Test, dan Verbal Fluency Test (VFT) untuk mengukur bahasa, 3) Digit span, symbol span, figural reproduction, dan Rey Auditory Verbal Learning Test (RAVLT) untuk mengukur domain memori, serta 4) Five Point Test (FPT) untuk mengukur fungsi eksekutif. ${ }^{14-16}$

Fungsi kognitif dikatakan baik jika didapatkan skor yang semakin tinggi dalam setiap tes, kecuali pada beberapa tes tertentu, yaitu pada TMT bagian waktu, Bourdon, dan FPT bagian perseverasi error, subjek yang memiliki skor semakin rendah memiliki fungsi yang semakin baik. Analisis skor fungsi kognitif dilakukan dengan menggunakan program SPSS-17 dengan uji statistik Mann-Whitney U test.

\section{HASIL}

Pada awal penelitian terdapat 6 subjek pada masing-masing kelompok, namun 2 subjek pada KE yang mengundurkan diri setelah 4 kali sesi CST serta 2 subjek pada KK yang tidak lanjut karena sakit. Akhirnya didapatkan 4 subjek pada tiap kelompok yang memiliki karakteristik yang hampir sama, yaitu berpendidikan rendah (Tabel 1). Secara pengujian statistik, tidak ada perbedaan skor yang signifikan pada kedua kelompok.

Tabel 1. Karakteristik Demografi Subjek $(n=8)$

\begin{tabular}{lcc}
\hline \multicolumn{1}{c}{ Variabel } & $\begin{array}{c}\text { Eksperimen } \\
(\mathbf{n = 4 )}\end{array}$ & $\begin{array}{c}\text { Kontrol } \\
(\mathbf{n}=\mathbf{4})\end{array}$ \\
\cline { 2 - 3 } & $\mathbf{n}(\mathbf{\%})$ & $\mathbf{n}(\mathbf{\%})$ \\
\hline Usia & $3(75)$ & $0(0)$ \\
- $\quad 61-65$ tahun & $1(25)$ & $2(50)$ \\
- $\quad 66-70$ tahun & $0(0)$ & $2(50)$ \\
- $>70$ tahun & & \\
Jenis Kelamin & $3(75)$ & $2(50)$ \\
- Laki-laki & $1(25)$ & $2(50)$ \\
- Perempuan & & \\
Pendidikan & $3(75)$ & $2(50)$ \\
- Tidak lulus SD & $0(0)$ & $1(25)$ \\
- SMP & $1(25)$ & $1(25)$ \\
- SMA/sederajat & &
\end{tabular}

Pada Tabel 2 terlihat perbedaan yang signifikan pada KE setelah intervensi CST. Terdapat 2 domain yang berbeda signifikan, yaitu domain atensi pada subtes TMT bagian total benar. Sum of ranks dari KE lebih tinggi dibandingkan KK, menunjukkan bahwa pada saat posttest, kemampuan untuk memproses

Neurona Vol. 36 No. 4 September 2019 informasi KE lebih baik dari KK. Selanjutnya adalah domain memori, pada subtes digit span bagian digit span backward dan digit span total. Sum of ranks dari KE lebih tinggi dibandingkan KK, menunjukkan bahwa pada saat posttest, KE memiliki kemampuan working memory dalam rangsang auditori yang lebih baik dibandingkan $\mathrm{KK}$.

Tabel 3 menunjukkan perbedaan skor pada kelompok eksperimen dan kontrol secara signifikan. Pada domain memori dengan subtes digit span forward, nilai pada kelompok eksperimen lebih tinggi dibandingkan kontrol yang berarti memiliki kemampuan working memory dalam rangsangan auditori yang lebih tinggi dibandingkan kelompok kontrol saat follow-up.

\section{PEMBAHASAN}

Penelitian ini menunjukkan bahwa terdapat perbedaan fungsi kognitif yang signifikan antara kelompok eksperimen dan kontrol pada domain atensi dengan subtes TMT (total benar) dan domain memori dengan subtes digit span (digit span backward dan digit span total) saat posttest. Pada saat follow-up juga terjadi perbedaan yang signifikan pada domain memori dengan subtes digit span (forward).

Digit span merupakan salah satu tes yang mengukur working memory dan alternating attention yang merupakan kemampuan individu untuk mengubah fokus atensinya ketika harus berpindah tugas. Atensi memiliki hubungan yang erat dengan working memory, sehingga jika atensi terganggu maka working memory juga akan terganggu, dan sebaliknya. ${ }^{17}$ Penelitian ini menunjukkan bahwa KE memiliki skor yang lebih tinggi dan berbeda signifikan setelah diberikan CST. Oleh karena itu dapat disimpulkan bahwa CST dapat meningkatkan fungsi atensi serta working memory pada lansia MCI.

Pada primary ageing, individu akan mengalami perubahan yang berhubungan dengan usia kronologis. Hal itu menyebabkan penurunan kecepatan mental yang akan berdampak terhadap proses kognitif pada perilaku atau tugas-tugas yang membutuhkan kecepatan, serta pada working memory, episodic memory, dan kemampuan fluid individu seperti bernalar dan menganalisis. ${ }^{18}$ Penurunan kecepatan mental 
Tabel 2. Skor Fungsi Kognitif pada Kedua Kelompok Pascaterapi

\begin{tabular}{|c|c|c|c|c|c|}
\hline Domain & Sub-Tes & ¿R Eksperimen & ¿R Kontrol & $\mathbf{U}$ & $\begin{array}{c}\text { Asymp. Sig. } \\
\text { (2 Tailed) }\end{array}$ \\
\hline \multirow[t]{10}{*}{ Atensi } & Trail Making Test $A$ & 17 & 19 & 7 & 0,886 \\
\hline & Trail Making Test B & 14 & 22 & 4 & 0,343 \\
\hline & Total benar & 26 & 10 & 0 & $0,029 *$ \\
\hline & Bourdon (kecepatan) & 15 & 21 & 5 & 0,486 \\
\hline & Bourdon (ketelitian) & 20 & 16 & 6 & 0,686 \\
\hline & Bourdon (konstansi) & 19 & 17 & 7 & 0,886 \\
\hline & Stroop (word) & 20 & 16 & 6 & 0,686 \\
\hline & Stroop (color) & 19,5 & 16,5 & 6,5 & 0,686 \\
\hline & Stroop $(C-W)$ & 21,5 & 14,5 & 4,5 & 0,343 \\
\hline & Stroop interference & 19 & 17 & 7 & 0,886 \\
\hline \multirow[t]{3}{*}{ Bahasa } & Boston Naming Test & 18 & 18 & 8 & 1 \\
\hline & Token Test & 16 & 20 & 6 & 0,686 \\
\hline & Verbal Fluency Test & 18 & 18 & 8 & 1 \\
\hline \multirow[t]{11}{*}{ Memori } & Digit span forward & 20,5 & 15,5 & 5,5 & 0,486 \\
\hline & Digit span backward & 26 & 10 & 0 & $0,029 *$ \\
\hline & Digit span sequences & 21 & 15 & 5 & 0,486 \\
\hline & Digit span total & 25,5 & 10,5 & 0,5 & $0,029 *$ \\
\hline & Symbol span forward & 24 & 12 & 2 & 0,114 \\
\hline & Symbol span backward & 18,5 & 17,5 & 7,5 & 0,886 \\
\hline & Symbol span total & 20,5 & 15,5 & 5,5 & 0,486 \\
\hline & Visual reproduction & 16,5 & 19,5 & 6,5 & 0,686 \\
\hline & RAVLT LOT & 13,5 & 22,5 & 3,5 & 0,2 \\
\hline & $R A V L T S T P R$ & 19 & 17 & 7 & 0,886 \\
\hline & RAVLT LTPR & 17 & 19 & 7 & 0,886 \\
\hline \multirow[t]{2}{*}{ Fungsi Eksekutif } & Five Point Test (unik) & 17 & 19 & 7 & 0,886 \\
\hline & Five Point Test (perseverasi) & 20 & 16 & 6 & 0,686 \\
\hline
\end{tabular}

*Uji Mann-Whitney, signifikan $\mathrm{p}<0,05$; $\Sigma \mathrm{R}$ : total ranking tiap kelompok. LOT: learning over trials; STPR: short term percent retention; LTPR: long term percent retention; RAVLT: Rey Auditory Verbal Learning Test.

ini membuat lansia kesulitan untuk mempelajari hal baru dan mempertahankannya. Oleh karena itu, perlu adanya maintenance pada kegiatan CST agar manfaat kegiatan CST dapat terus dirasakan oleh subjek yang mengikutinya. Penelitian sebelumnya menyebutkan bahwa sesi lanjutan setelah kegiatan utama CST selesai dapat membantu memperbaiki fungsi memori. ${ }^{19}$ Hal ini berkaitan karena sesi lanjutan tersebut memiliki tema yang sama, namun aktivitas didalamnya dapat disesuaikan untuk mencegah kejenuhan pada subjek.

Fungsi memori yang stabil atau bahkan meningkat, akan membantu lansia dengan MCI menjalani aktivitas sehari-harinya. Pada lansia dengan MCI yang mengarah kepada penyakit Alzheimer, maka memori episodik merupakan bagian memori yang paling terkena dampak. ${ }^{20}$ Lansia dengan MCI akan mulai kesulitan untuk mengingat kegiatan yang baru saja dikerjakannya, wajah atau sosok orang yang baru saja berkenalan dengannya, dan sebagainya. Oleh karena itu, ia menyadari bahwa dirinya mengalami penurunan memori, sehingga menimbulkan kekhawatiran jika tidak memiliki kemampuan daya ingat seperti sebelumnya. Perubahan-perubahan tersebut dapat membuat seseorang merasa tidak percaya diri. ${ }^{21}$ Dengan mengikuti kegiatan CST secara rutin, lansia dengan MCI diharapkan dapat memperoleh manfaat 
Tabel 3. Skor Fungsi Kognitif pada Kedua Kelompok Satu Bulan Pascaterapi (Follow-Up)

\begin{tabular}{|c|c|c|c|c|c|}
\hline Domain & Sub-Tes & ¿ R Eksperimen & $\Sigma$ R Kontrol & $\mathbf{U}$ & $\begin{array}{c}\text { Asymp. Sig. } \\
\text { (2 tailed) }\end{array}$ \\
\hline \multirow[t]{10}{*}{ Atensi } & Trail Making Test $A$ & 16 & 20 & 6 & 0,686 \\
\hline & Trail Making Test B & 11 & 25 & 1 & 0,057 \\
\hline & Total benar & 23 & 13 & 3 & 0,2 \\
\hline & Bourdon (kecepatan) & 15 & 21 & 5 & 0,486 \\
\hline & Bourdon (ketelitian) & 21 & 15 & 5 & 0,486 \\
\hline & Bourdon (konstansi) & 17 & 19 & 7 & 0,886 \\
\hline & Stroop (word) & 22 & 14 & 4 & 0,343 \\
\hline & Stroop (color) & 18,5 & 17,5 & 7,5 & 0,886 \\
\hline & Stroop $(C-W)$ & 21 & 15 & 5 & 0,486 \\
\hline & Stroop interference & 16 & 20 & 6 & 0,686 \\
\hline \multirow[t]{3}{*}{ Bahasa } & Boston Naming Test & 21 & 15 & 5 & 0,486 \\
\hline & Token Test & 15 & 21 & 5 & 0,486 \\
\hline & Verbal Fluency Test & 18 & 18 & 8 & 1 \\
\hline \multirow[t]{11}{*}{ Memori } & Digit span forward & 25,5 & 10,5 & 0,5 & $0,029 *$ \\
\hline & Digit span backward & 21,5 & 14,5 & 4,5 & 0,343 \\
\hline & Digit span sequences & 20 & 16 & 6 & 0,686 \\
\hline & Digit span total & 23 & 13 & 3 & 0,2 \\
\hline & Symbol span forward & 12 & 24 & 2 & 0,114 \\
\hline & Symbol span backward & 17 & 19 & 7 & 0,886 \\
\hline & Symbol span total & 13,5 & 22,5 & 3,5 & 0,2 \\
\hline & Visual reproduction & 19,5 & 16,5 & 6,5 & 0,686 \\
\hline & RAVLT LOT & 20 & 16 & 6 & 0,686 \\
\hline & RAVLT STPR & 20 & 16 & 6 & 0,686 \\
\hline & RAVLT LTPR & 18,5 & 17,5 & 7,5 & 0,886 \\
\hline Fungsi & Five Point Test (unik) & 14 & 22 & 4 & 0,343 \\
\hline Eksekutif & Five Point Test (perseverasi) & 23 & 13 & 3 & 0,2 \\
\hline
\end{tabular}

*Uji Mann-Whitney, signifikan $\mathrm{p}<0,05 ; \Sigma \mathrm{R}$ : total ranking tiap kelompok; LOT: learning over trials; STPR: short term percent retention; LTPR: long term percent retention; RAVLT: Rey Auditory Verbal Learning Test.

pada fungsi kognitif dan juga fungsi sosialnya seharihari.

Dalam penelitian ini, terlihat bahwa faktor pendidikan cukup berpengaruh dalam proses diskusi yang diharapkan terjadi dalam kegiatan CST. Tiga dari empat subjek CST merupakan lansia yang tidak lulus sekolah dasar, sehingga kurang memiliki pengetahuan dan minat yang luas. Akibatnya, proses diskusi tidak selalu terjadi dua arah. Adanya individual differences membuat masing-masing individu memiliki respons yang beraneka ragam terhadap intervensi CST. Salah satu faktor yang memengaruhi fungsi kognitif seseorang adalah individual differences. ${ }^{22}$ Dalam hal ini, kepribadian termasuk motivasi dan sikap dari seseorang dapat berkontribusi pada fungsi kognitifnya. Pada penelitian ini terdapat lansia yang mengalami peningkatan skor, walaupun memiliki tingkat pendidikan yang rendah.

Pada penelitian ini, 1 sesi tambahan dengan tema kerabat yang diuji cobakan dapat diterima oleh subjek. Respons setiap lansia juga bergantung pada individual differences, bahwa ada lansia yang memiliki kekecewaan terhadap kerabatnya dan belum dapat menerima dirinya tinggal di panti.

Untuk menghadapi karakteristik subjek yang berbeda-beda, fasilitator CST dapat diberikan pelatihan sebelum memimpin CST. Fasilitator juga hendaknya menyesuaikan materi dengan tingkat 
pendidikan dan memperhatikan keterbatasan fisik masing-masing lansia. Beberapa kegiatan yang ditawarkan CST, membutuhkan motorik kasar dan halus pada anggota tubuh bagian atas. Oleh karena itu, fasilitator harus mempersiapkan kegiatan yang dapat dilakukan oleh seluruh peserta tanpa terkecuali.

Berdasarkan wawancara dengan peserta intervensi, seluruh subjek merasa CST bermanfaat, antara lain pemanfaatan waktu luang. Setelah mengikuti kegiatan CST, subjek merasa lebih saling mengenal satu sama lain, mengingat masa muda, dan perlahan membuka diri dengan subjek lain. Dengan menuliskan nama orang-orang terdekatnya, subjek merasa masih dikelilingi oleh banyak orang yang baik serta sangat bersyukur walaupun tinggal di panti. Faktor psikososial yang mendukung merupakan salah satu prediktor yang dapat memengaruhi resiliensi serta kesehatan fisik dari lansia perempuan yang berstatus janda. ${ }^{23}$ Kim dkk menyebutkan bahwa kegiatan stimulasi otak bermanfaat bukan hanya untuk perbaikan fungsi kognitif, melainkan juga kualitas hidup pesertanya. ${ }^{24}$

Keterbatasan dalam penelitian ini adalah pemilihan sampel secara non-random sampling. Untuk meningkatkan probabilitas akurasi dari hasil penelitian, dibutuhkan proses pengambilan sampel secara random. ${ }^{25}$ Pada penelitian ini subjek diambil sesuai keberadaannya di panti, sehingga tidak dapat dilakukan randomisasi dan pemasangan secara seimbang untuk membuat kedua kelompok ekuivalen. Untuk mengatasinya, peneliti melakukan uji beda skor pretest pada kedua kelompok untuk melihat nilai baseline yang berbeda secara signifikan.

Keterbatasan lainnya adalah jumlah sampel yang terbatas, sehingga tidak terpenuhinya asumsi parametrik dalam penelitian ini. Selain itu desain penelitian ini bersifat studi lapangan, besar kemungkinan adanya variabel lain di luar CST yang tidak terukur namun berkontribusi terhadap skor fungsi kognitif. Intervensi CST juga merupakan terapi kelompok yang didesain agar lansia dapat memilih kegiatan atau aktivitas yang ingin dilakukan, walaupun telah dipersiapkan sebelumnya. Waktu yang terbatas atau terkadang bertabrakan dengan kegiatan panti yang lain juga membuat aktivitas yang sudah direncanakan tidak diteruskan. Kegiatan CST dilakukan hanya 2 kali dalam seminggu, sehingga kegiatan lain di luar CST tidak dapat dikontrol walaupun tetap dilakukan pencatatan. Namun hal-hal seperti itu menyulitkan perlakuan kontrol eksperimen yang sangat ketat.

\section{KESIMPULAN}

Cognitive stimulation therapy dapat menstabilkan dan/meningkatkan fungsi kognitif pada lansia dengan MCI, khususnya pada atensi dan working memory. Modul intervensi CST asli dapat diterapkan pada lansia dengan MCI di panti wreda Indonesia dengan beberapa adaptasi dan modifikasi yang disesuaikan dengan kondisi lansia di tiap panti.

\section{UCAPAN TERIMA KASIH}

Terima kasih kepada Yuda Turana, Tara Sani, dan Lidia Laksana Hidajat atas bimbingan, waktu, dan memberikan saran yang konstruktif bagi penelitian ini.

\section{DAFTAR PUSTAKA}

1. Steiner $\mathrm{ABQ}$, Jacinto AF, Mayoral VF, Brucki SMD, Citero VA. Mild cognitive impairment and progression to dementia of Alzheimer's disease. Rev Assoc Med Bras. 2017;63(7):651-5.

2. Michaud TL, Su D, Siahpush M, Murman D. The risk of incident mild cognitive impairment and progression to dementia considering mild cognitive impairment subtypes. Dement Geriatr Cogn Extra. 2017;7(1):15-29.

3. Horr T, Pillai JA, Rapport BJM. What can we offer patients with mild cognitive impairment? Cleveland Clin J Med. 2015;82(10):650-2.

4. Moro V, Condoleo MT, Sala F, Pernigo S, Moretto G, Gambina G. Cognitive stimulation in a-MCI: an experimental study. Am J Alzheimer's Dis. 2012;27(2):121-30.

5. Toh HM, Ghazali SE, Subramaniam P. The acceptability and usefulness of cognitive stimulation therapy for older adults with dementia: a narrative review. Int J Alzheimers Dis. 2016;2016:5131570.

6. Streater A, Spector A, Aguirre, Orrell M. Cognitive stimulation therapy (CST) for people with dementia in observational study. British J Occupational Ther. 2016:79(12):762-7.

7. Qiu CX, Johansson G, Zhu FQ, Kivipelto M, Winblad B. Prevention of cognitive decline in old age-varying effects of interventions in different population. Ann Transl Med. 2019:7(Supl 3):S142. 
8. Aquirre E, Spector A, Orrell M. Guidelines for adapting cognitive stimulation therapy to other cultures. Clin Interv Aging. 2014;9:1003-7.

9. Toh H, Ghazali SE, Subramaniam P. The acceptability and usefulness of cognitive stimulation therapy (CST) for older adults with dementia: a narrative review. Int J Alzheimer's Dis. 2016;(2):1-11.

10. Badan Pusat Statistik. Statistik penduduk lanjut usia; 2018.

11. Wreksoatmodjo BR. Perbedaan karakteristik lanjut usia yang tinggal di keluarga dengan yang tinggal di panti di Jakarta Barat. CDK-209. 2013;40(10):73845.

12. Fu C, Li Z, Mao Z. Association between social activities and cognitive function among the elderly in China: A cross-sectional study. Int J Environ Res Public Health. 2018;15(2):231.

13. Strauss E, Sherman EMS, Spreen O. A compendium of neuropsychological tests: administration, norms, and commentary. Edisi Ke-3. New York; Oxford University Press: 2006. h. 62-3.

14. Bastiannse R, Raaijmakers S, Satoer D, Brink EV. The multilingual toke test. Aphasiology. 2015;30(4):508.

15. Regia L, Franch V, Pousa L, Perxas C, Rodas T, Olmo G. The trail making test. Assessment. 2017;24(2):18396.

16. Aguirre E, Spector A, Streater A, Hoe J, Woods B, Orrell M. Making a difference 2. An evidence-based group programme to offer maintenance cognitive stimulation therapy (CST) to people with dementia. United Kingdom: Hawker Publications; 2012.

17. Stigchel V, Olivers CNL. The flexible nature of the interaction between attention and working memory. $\mathrm{J}$ Cognition. 2019:2(1):31.
18. Woods B, Clare L. Psychological interventions with people with dementia. Handbook of the clinical psychology of ageing. England: John Wiley \& Sons; 2015:2:523-48.

19. Orrell M, Spector A, Thorgrimson L, Woods B. A pilot study examining the effectiveness of maintenance Cognitive Stimulation Therapy (MCST) for people with dementia. Int J Geriatric Psych. 2005;20(5):44651 .

20. Larouche E, Hudon C, Goulet S. Potential benefits of mindfulness-based interventions in mild cognitive impairment and Alzheimer's disease: an interdisciplinary perspective. Behavioral Brain Res. 2014;1(276):199-12.

21. Santrock J. Life-span development. New York: McGraw Hill. 2015;15:1-768.

22. Boogert NJ, Madden JR, Feeron JM, Thomton A. Measuring and understanding individual deifferences in cognition. Philos Trans R Soc Lond B Biol Sci. 2018:373(1756):1-10.

23. Bennett KM, Morselli D, Spahni S, Chiello P. Trajectories of resilience among widows: a latent transition model. Aging Ment Health. 2019;2019:1-8.

24. Kim KY, Han JW, So YS, Seo JY, Kim YJ, Park JH. Cognitive stimulation as therapeutic modality for dementia: a meta-analysis. Psychiatry Investig. 2017:14(5):626-39.

25. Gravetter FJ, Walnau LB. Statistic for the behavioral science. Edisi ke-9. Canada: Wadsworth-Cengage Learning. 2013. h. 1-792 